\title{
Article \\ Numerical Investigations through ANNs for Solving COVID-19 Model
}

\author{
Muhammad Umar ${ }^{1}$, Zulqurnain Sabir 1,*, Muhammad Asif Zahoor Raja ${ }^{2}$, Shumaila Javeed ${ }^{3, *(D),}$ \\ Hijaz Ahmad ${ }^{4,5}$, Sayed K. Elagen ${ }^{6}$ and Ahmed Khames ${ }^{7} \mathbb{D}$
}

1 Department of Mathematics and Statistics, Hazara University, Mansehra 21300, Pakistan; umar_maths@hu.edu.pk

2 Future Technology Research Center, National Yunlin University of Science and Technology, 123 University Road, Section 3, Douliou 64002, Taiwan; rajamaz@yuntech.edu.tw

3 Department of Mathematics, Islamabad Campus, COMSATS University Islamabad, Park Road, Islamabad 45550, Pakistan

4 Department of Computer Engineering, Biruni University, Istanbul 34025, Turkey; hijaz555@gmail.com

5 Section of Mathematics, International Telematic University Uninettuno, Corso Vittorio Emanuele II, 39, 00186 Roma, Italy

6 Department of Mathematics and Statistics, College of Science, Taif University, P.O. Box 11099, Taif 21944, Saudi Arabia; skhalil@tu.edu.sa

7 Department of Pharmaceutics and Industrial Pharmacy, College of Pharmacy, Taif University, P.O. Box 11099, Taif 21944, Saudi Arabia; A.khamies@tu.edu.sa

* Correspondence: zulqurnain_maths@hu.edu.pk (Z.S.); shumaila_javeed@comsats.edu.pk (S.J.)

check for

updates

Citation: Umar, M.; Sabir

Z.; Raja, M.A.Z.; Javeed, S.;

Ahmad, H.; Elagen, S.K.; Khames, A.

Numerical Investigations through

ANNs for Solving COVID-19 Model.

Int. J. Environ. Res. Public Health 2021,

18, 12192. https://doi.org/10.3390/

ijerph182212192

Academic Editors: Jahar Bhowmik and Paul B. Tchounwou

Received: 4 September 2021

Accepted: 10 November 2021

Published: 20 November 2021

Publisher's Note: MDPI stays neutral with regard to jurisdictional claims in published maps and institutional affiliations.

Copyright: (c) 2021 by the authors. Licensee MDPI, Basel, Switzerland. This article is an open access article distributed under the terms and conditions of the Creative Commons Attribution (CC BY) license (https:/ / creativecommons.org/licenses/by/ $4.0 /)$.
Abstract: The current investigations of the COVID-19 spreading model are presented through the artificial neuron networks (ANNs) with training of the Levenberg-Marquardt backpropagation (LMB), i.e., ANNs-LMB. The ANNs-LMB scheme is used in different variations of the sample data for training, validation, and testing with $80 \%, 10 \%$, and $10 \%$, respectively. The approximate numerical solutions of the COVID-19 spreading model have been calculated using the ANNs-LMB and compared viably using the reference dataset based on the Runge-Kutta scheme. The obtained performance of the solution dynamics of the COVID-19 spreading model are presented based on the ANNs-LMB to minimize the values of fitness on mean square error (M.S.E), along with error histograms, regression, and correlation analysis.

Keywords: COVID-19 spreading model; artificial neural networks; Levenberg-Marquardt backpropagation; reference dataset; numerical results

\section{Introduction}

The development of science, both over technology, as well as information, is related to the human's heathy life. In fact, there are numerous complications that are not considered easy in an individual's life. In the health sector, a number of infectious diseases are produced by the bacterial viruses. The diseased infections are a big danger for the society that always disturbed the economies of the countries, destroyed the sector of education and demolished the tourism industry. A novel Coronavirus is a dangerous transmittable virus discovered at the end of the 19th century and spread all around the world [1]. Many peoples died from coronavirus disease (COVID-19) and the positive cases, along with the recovery rate, has also a great number [1]. The common COVID-19 symptoms are runny noses, sore throats, coughs, headaches and fever, or severe breathing symptoms, such as bleeding, high fever, cough with phlegm, shortness of breath, and chest pain [2].

In recent decades, the researchers considered a favorite topic examining the dynamics of coronavirus, and they presented many recommendations. Donders et al. [3] expressed the International Society of Infectious Disease in Obstetrics and Gynecology (ISIDOG) based recommendations for the COVID-19. Wang [4] suggested a mathematical COVID-19 
system based on the limitations, applications, and potentials. Rhodes et al. [5] designed a mathematical system to express the public difficulties of the infection control of coronavirus. Javeed et al. [6] presented a novel model for COVID-19, including the effects of government strategies and comparative analysis of different countries regarding prevention of disease. Jewell et al. [7] described the potential impacts of disruption-based human immunodeficiency virus (HIV) programs in Africa produced by the coronavirus. Sánchez et al. [8] suggested a fractal susceptible, infection, treatment, and recovery (SITR) nonlinear model to express the coronavirus dynamics. Khrapov et al. [9] comparatively analyzed the mathematical system using the dynamics of the coronavirus epidemic growth in various countries. Elsonbaty et al. [10] proposed a dynamical discrete SITRs fractional system related to coronavirus. Thompson [11] introduced the epidemiologic system that is considered a significant tool based on the coronavirus interferences. Umer et al. [12,13] calculated the numerical results based on the swarming and heuristic schemes for solving the nonlinear SITR model based on the coronavirus.

Kharis et al. [14] studied a mathematical model, which plays a vital role to avoid the spread of viruses. Yulida [15] explained that a significant role of mathematics is observed to explore the outbreak of the dynamics of diseases, spreading and forecasting patterns to deal stratagems called as epidemiological mathematics. Moreover, the solutions of some mathematical models are presented analytically that involves epidemic diseases. Hence, it is important to gain the numerical designs for such problems. Therefore, the stochastic computational schemes using the artificial neuron networks (ANNs) with the novel features of the Levenberg-Marquardt backpropagation (LMB), i.e., ANNs-LMB, is implemented to solve the nonlinear COVID-19 spreading model. The stochastic procedures of ANNs-LMB have never been applied for solving the nonlinear COVID-19 spreading model. The data ratio is adjusted for three cases of the coronavirus spreading model are $80 \%, 10 \%$, and $10 \%$ for training, testing and validation, respectively. The numerical measures are performed using the ANNs-LMB for solving the coronavirus spreading model and comparison will be performed through the reference dataset based Runge-Kutta scheme [16]. Some reputed used of stochastic procedures are the delay differential models [16,17], multi-fractional systems [18-20], prey-predator model [21], infection based HIV system [22], singular functional systems [23], Thomas-Fermi equation [24], heat conduction model [25], mosquito dispersal system [26], and periodic singular model [27,28].

The aim of the study is to present a design of computing framework based on artificial neural network trained with Livenberg-Marquardt backpropagation (ANNs-LMB) for analysis of coronavirus spreading model. While a lot of literature is available on the internet used for reliable and accurate prediction of coronavirus spreading in different regions of the world using sophisticated computing paradigm of neural networks, deep-learning, and transfer learning, combined with deterministic and stochastic optimization solver for global and local search, including a novel hybrid time series model of COVID-19 [29], neural network prediction of COVID-19 pandemic at the Brazilian Amazon [30], integrated neuro-evolution heuristics approach [31], transfer learning based computing [12], deep neural networks [32], nonlinear autoregressive networks [33], and radial base networks [34]. However, the potentials of the proposed ANNs-LMB to solve the coronavirus spreading model are presented as follows for better understanding of the contribution:

- Artificial intelligence (AI) knacks-based computational procedure via neural networks models learned with Livenberg-Marquardt algorithm is introduced and implemented to solve nonlinear coronavirus spreading model represented with 7 classes based systems of ordinary differential equations (ODEs).

- The comparison of the results obtained through designed computing ANNs-LMB with numerical solutions are found in good agreement on the basis of absolute error (AE) values, which approve the value, worth and significance of the ANNs-LMB to solve the nonlinear coronavirus spreading model. 
- $\quad$ The performance or convergence curves on mean square error (MSE), regression metric calculations of correlation index, and error histograms (EHs) through exhaustive simulations further indorse the reliability and consistency of the ANNs-LMB scheme.

The remaining parts are organized as: The designed methodology based ANNs-LMB is provided in Section 2, numerical simulations are presented in Section 3, and concluding remarks are provided in Section 4.

\section{Material and Methods}

The material and methodologies presented here are described in three portions for solving the nonlinear coronavirus spreading model as follows.

The nonlinear COVID-19 spreading model has seven classes, susceptible $(S(y))$, exposed population $(E(y))$, infected $(I(y))$, removed $(R(y))$, total population $(N(y))$, public perception $(D(y))$, and cumulative case $(C(y))$, along with the initial conditions (ICs), given as [28]:

$$
\begin{cases}S^{\prime}(y)=-\frac{\beta_{0} E(y) S(y)}{N(y)}-\frac{\beta(y) I(y) S(y)}{N(y)}-\mu S(y), & S(0)=I_{1} \\ E^{\prime}(y)=\frac{\beta_{0} E(y) S(y)}{N(y)}+\frac{\beta(y) I(y) S(y)}{N(y)}-(\mu+\sigma) E(y), & E(0)=I_{2} \\ I^{\prime}(y)=\sigma E(y)-(\mu+\gamma) I(y), & I(0)=I_{3} \\ R^{\prime}(y)=-\mu R(y)+\gamma I(y), & R(0)=I_{4} \\ N^{\prime}(y)=-\mu N(y), & N(0)=I_{5} \\ D^{\prime}(y)=-\lambda D(y)+d \gamma I(y), & D(0)=I_{6} \\ C^{\prime}=\sigma E(y), & C(0)=I_{7} .\end{cases}
$$

where $\mu, \beta_{0}$, and $\sigma$ are the emigration, initial transmission, and latent rates, whereas the transmission rates at time $y$, public reaction, infected, and severe cases are $\beta(y), \lambda, \gamma$, and $d$. The ICs are $I_{1}, I_{2}, I_{3}, I_{4}, I_{5}, I_{6}$, and $I_{7}$.

In the first step, the necessary details of the numerical procedure of the Runge-Kutta solver are provided which are used to create dataset for the system (1). In the second part, designed ANNs-LMB computing platform in terms of networks modeling, layer structure, and backpropagation algorithm are provided, while, in the third step, implementation procedures of the proposed ANNs-LMB to solve the nonlinear coronavirus spreading model is provided.

The reference datasets for different scenario of nonlinear coronavirus spreading model represented with 7 class-based systems of ODEs as portrayed in the set of equations in Equation (1) are calculated by exploiting the numerical strength of Adams solver using 'NDSolve' routine for solution of differential equations in Mathematica software package in Microsoft Windows 10 environment. The default parameter settings of Adams procedure, i.e., good accuracy, tolerances, stoppage criteria, etc., is used for execution. The dataset generated is used for modeling the networks with different distributions of data in training, testing, and validation samples for each case of the nonlinear corona virus spreading system (1).

The appropriate work flow structure of proposed methodology ANNs-LMB in terms of problem, layer structure, and results description with performance analysis, and optimization procedures are illustrated in Figure 1. 


\section{Methodology}

\section{Reference Solutions}

Design dataset for the comparative surveys using the reference dataset for the nonlinear COVID-19 spreading model

Intelligent computing framework

Multi-layer design of ANNs-LMB to solve the nonlinear COVID-19 spreading model

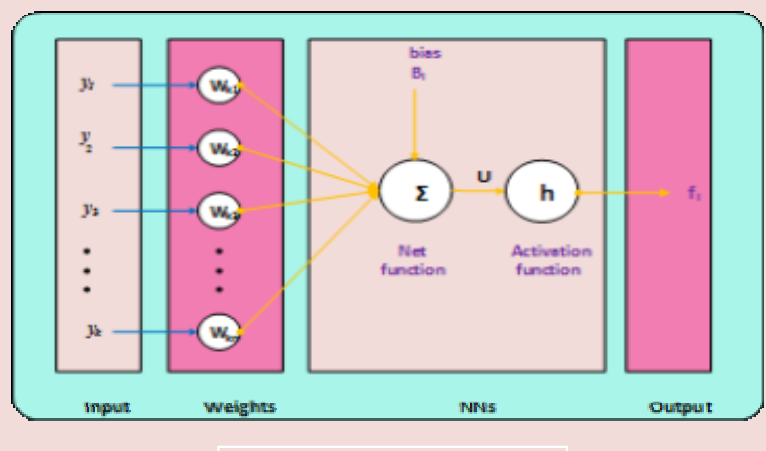

Neuron Model

\section{Simulations of Results}

Results overlapping based on the ANNs-

$\mathrm{LMB}$ and the reference solutions for the AE

values to solve the

nonlinear COVID-19

spreading model
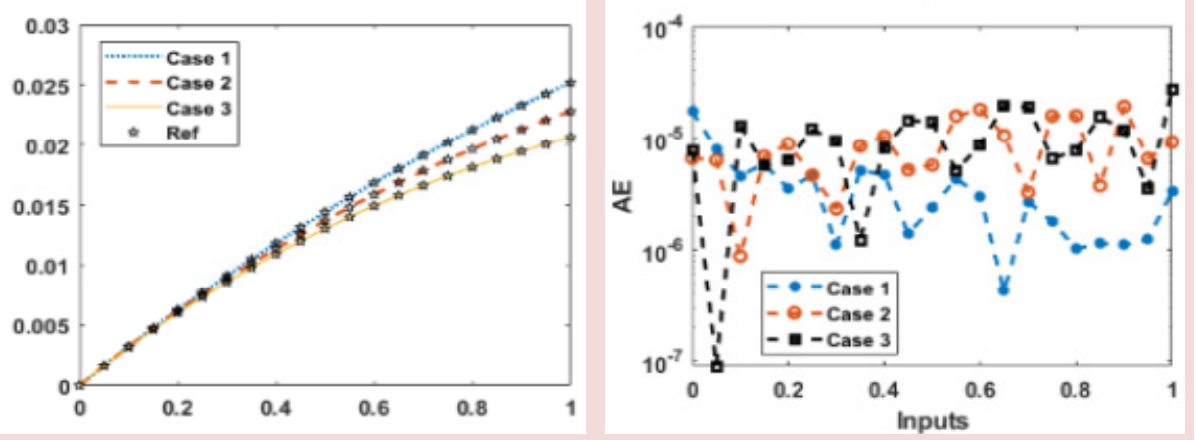

Result Comparison

AE

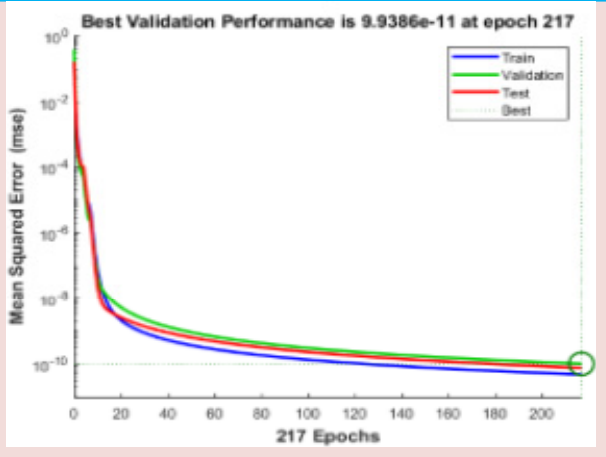

Performance

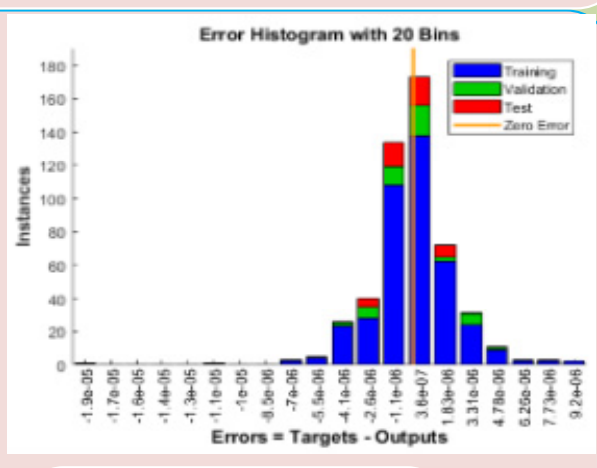

EHS

Figure 1. Workflow diagram using the ANNs-LMB to solve the nonlinear COVID-19 spreading model.

The proposed model for a single neuron representation is shown in Figure 2. The buildin 'nftool' command available in the neural network toolbox in MATLAB software package in Microsoft Windows 10 environment is used for the training, testing, and validation with $80 \%, 10 \%$, and $10 \%$ samples, respectively, for formulation of networks to find the approximate solutions for nonlinear coronavirus spreading model represented for the 7 class-based systems of ordinary differential equations as given in set (1). Moreover, the number of epochs executed for each problem is set after detailed simulations, as per the procedure provided in references $[35,36]$. 


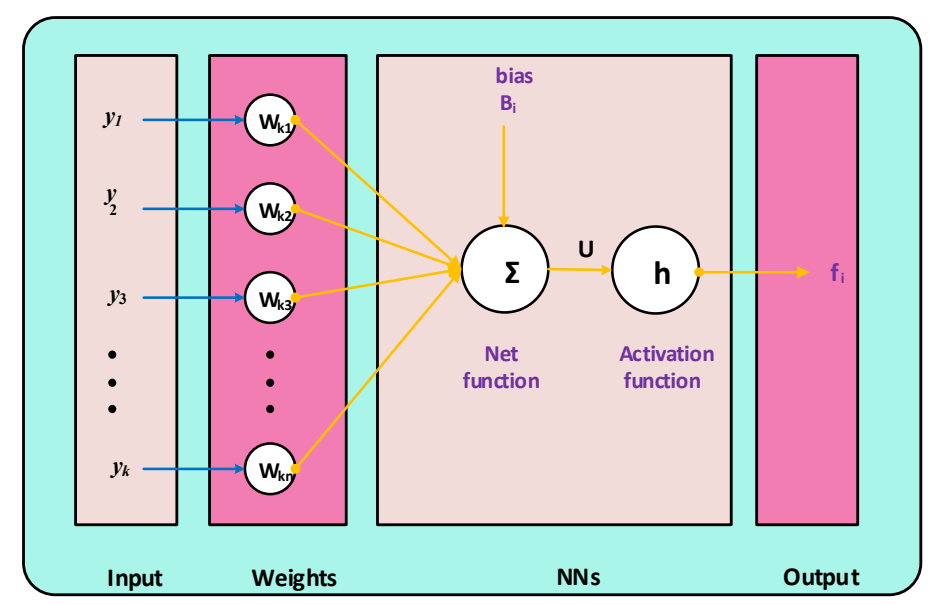

Figure 2. Structure of a single neuron based on the ANNs-LMB.

\section{Numerical Experimentation with Interpretation of Results}

This section presents the numerical performances of three cases based on the nonlinear coronavirus spreading model using the proposed ANNs-LMB. The mathematical form of each case is given as:

Case 1. Considering the nonlinear coronavirus spreading model with the appropriate values is shown as:

$$
\begin{cases}S^{\prime}(y)=-\frac{0.5 E(y) S(y)}{N(y)}-\frac{0.6 I(y) S(y)}{N(y)}-0.0205 S(y), & S(0)=0.9, \\ E^{\prime}(y)=\frac{0.5 E(y) S(y)}{N(y)}+\frac{0.6(y) I(y) S(y)}{N(y)}-\left(0.0205+\frac{1}{3}\right) E(y), & E(0)=0.1, \\ I^{\prime}(y)=\frac{1}{3} E(y)-\left(0.0205+\frac{1}{5}\right) I(y), & I(0)=0, \\ R^{\prime}(y)=-0.0205 R(y)+\frac{1}{5} I(y), & R(0)=0, \\ N^{\prime}(y)=-0.0205 N(y), & N(0)=14, \\ D^{\prime}(y)=-\frac{1}{11.2} D(y)+0.04 \gamma I(y), & D(0)=0, \\ C^{\prime}(y)=\frac{1}{3} E(y), & C(0)=0 .\end{cases}
$$

Case 2. Considering the nonlinear coronavirus spreading model with the appropriate values is shown as:

$$
\begin{cases}S^{\prime}(y)=-\frac{0.5 E(y) S(y)}{N(y)}-\frac{0.6 I(y) S(y)}{N(y)}-0.1205 S(y), & S(0)=0.9, \\ E^{\prime}(y)=\frac{0.5 E(y) S(y)}{N(y)}+\frac{0.6(y) I(y) S(y)}{N(y)}-\left(0.1205+\frac{1}{3}\right) E(y), & E(0)=0.1, \\ I^{\prime}(y)=\frac{1}{3} E(y)-\left(0.1205+\frac{1}{5}\right) I(y), & I(0)=0, \\ R^{\prime}(y)=-0.1205 R(y)+\frac{1}{5} I(y), & R(0)=0, \\ N^{\prime}(y)=-0.1205 N(y), & N(0)=14, \\ D^{\prime}(y)=-\frac{1}{11.2} D(y)+0.04 \gamma I(y), & D(0)=0, \\ C^{\prime}(y)=\frac{1}{3} E(y), & C(0)=0 .\end{cases}
$$

Case 3. Considering the nonlinear coronavirus spreading model with the appropriate values is shown as:

$$
\begin{cases}S^{\prime}(y)=-\frac{0.5 E(y) S(y)}{N(y)}-\frac{0.6 I(y) S(y)}{N(y)}-0.2205 S(y), & S(0)=0.9, \\ E^{\prime}(y)=\frac{0.5 E(y) S(y)}{N(y)}+\frac{0.6(y) I(y) S(y)}{N(y)}-\left(0.2205+\frac{1}{3}\right) E(y), & E(0)=0.1, \\ I^{\prime}(y)=\frac{1}{3} E(y)-\left(0.2205+\frac{1}{5}\right) I(y), & I(0)=0, \\ R^{\prime}(y)=-0.2205 R(y)+\frac{1}{5} I(y), & R(0)=0, \\ N^{\prime}(y)=-0.2205 N(y), & N(0)=14, \\ D^{\prime}(y)=-\frac{1}{11.2} D(y)+0.04 \gamma I(y), & D(0)=0, \\ C^{\prime}(y)=\frac{1}{3} E(y), & C(0)=0 .\end{cases}
$$


The numerical values to solve each class of the nonlinear coronavirus spreading model are provided through the procedures of ANNs-LMB with input interval [0,1] and 0.01 step size. The designed ANNs-LMB procedures is selected as a larger part, i.e., for (training $-80 \%$ ), (validation-10\%), and (testing-10\%), respectively. The hidden neurons have been selected as 10 for each case of the nonlinear coronavirus spreading model [37], and the obtained numerical performances through the ANNs-LMB to solve each case of the model are presented in Figure 3 based on the single layer structure [38].

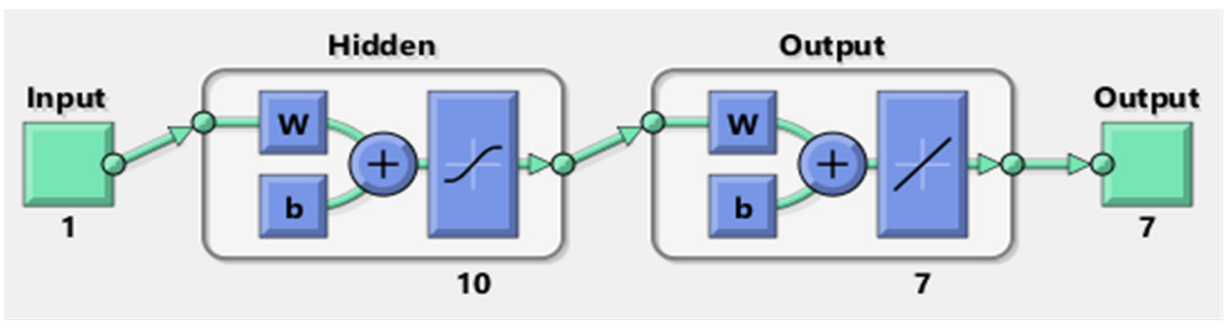

Figure 3. Proposed ANNs-LMB to solve the nonlinear COVID-19 spreading model with a single input layer, a single hidden layer with 10 number of neurons, and a single output layer with 7 outputs.

The plots of the ANNs-LMB to solve the nonlinear coronavirus spreading model are drawn in Figures 4-7. The proficient performances, as well as states of transition, to solve each class of the nonlinear coronavirus spreading model is drawn in Figure 4 . The obtained numerical performances are plotted based on the M.S.E for testing, best curves, validation, and training in Figure $4 \mathrm{a}-\mathrm{c}$ to solve the nonlinear coronavirus spreading model. These illustrations show that ANNs-LMB to solve each nonlinear coronavirus spreading model at epochs numbers 67, 195, and 217 with MSE almost $1.37 \times 10^{-9}, 9.62 \times 10^{-11}$ and $9.93 \times 10^{-11}$, respectively. Figure $4 \mathrm{~d}-\mathrm{f}$ indicates the gradient performances using the ANNs-LMB to solve the nonlinear coronavirus spreading model which found around $9.98 \times 10^{-8}, 9.99 \times 10^{-8}$, and $9.92 \times 10^{-8}$ for the respective three cases. These graphs show the precision, convergence, and accuracy of the ANNs-LMB to solve each variant of the nonlinear coronavirus spreading model. The plots based on the fitting curves to solve each variant of the nonlinear coronavirus spreading model are drawn in Figure $5 \mathrm{a}-\mathrm{c}$, which show the accuracy through the comparative ANNs-LMB results with the reference data. The error plots are demonstrated through the measures of training, testing, and verification and using the ANNs-LMB to solve each variant of the nonlinear coronavirus spreading model. The EHs plots are provided in Figure $5 \mathrm{~d}-\mathrm{f}$, which show that the errors lie around $-2.2 \times 10^{-6}, 1.0 \times 10^{-7}$, and $1.01 \times 10^{-7}$ for the three respective cases of coronavirus spread model. The regression illustrations are provided in Figures $6-8$ based on each variant of the nonlinear coronavirus spreading model. These correlation plots are presented with the regression index value close to unity in each case. The correlation values are observed nearly equal to 1 for each case of the nonlinear coronavirus spreading model which demonstrate near to perfect modeling of the solution dynamics of the system. The testing, training, and authentication plots indicate the accuracy and precision of the ANNs-LMB to solve each class of the nonlinear coronavirus spreading model. Furthermore, the convergence through the MSE procedures is sanctioned through the epochs, training, verification, backpropagation presentations, complexity, and testing measures are drawn in Table 1 to solve the nonlinear coronavirus spreading model. 


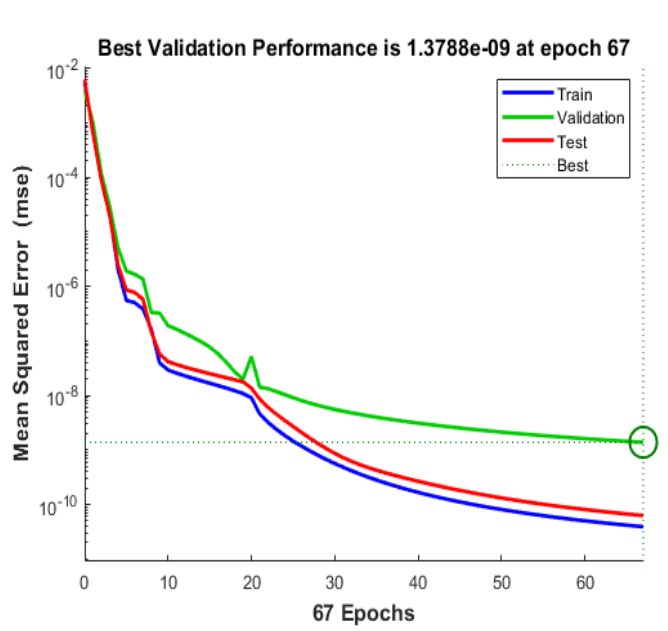

(a) Case 1 M.S.E

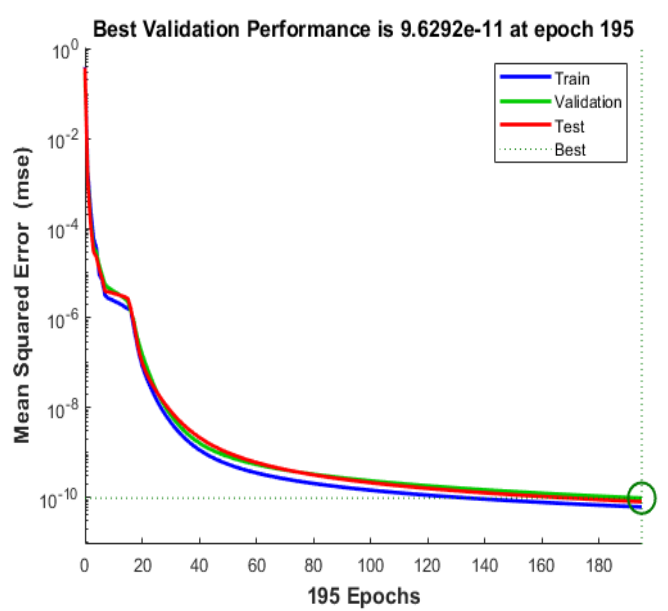

(b) Case 2 M.S.E

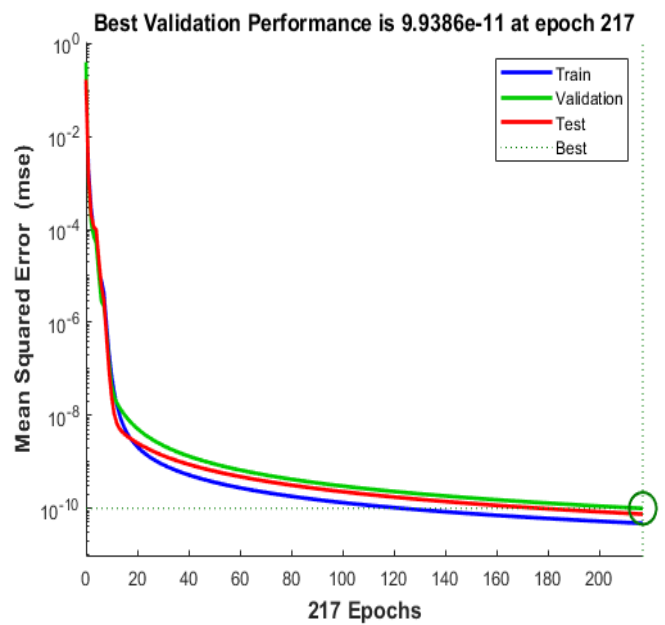

(c) Case 3 M.S.E

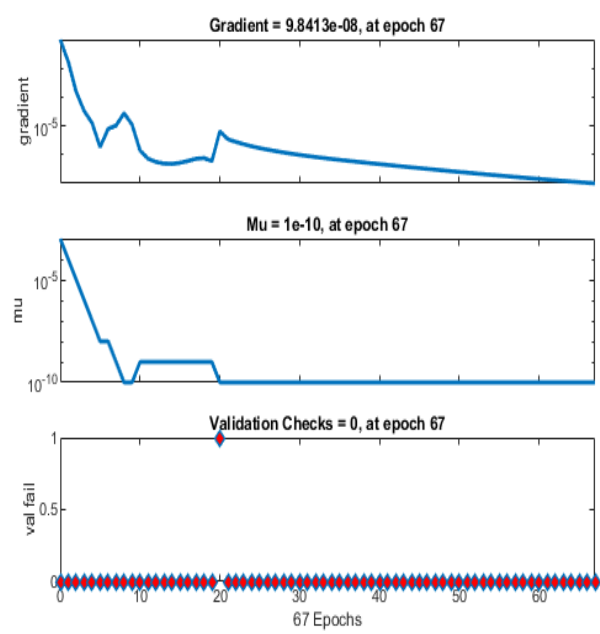

(d) Case $1 \mathrm{EHs}$

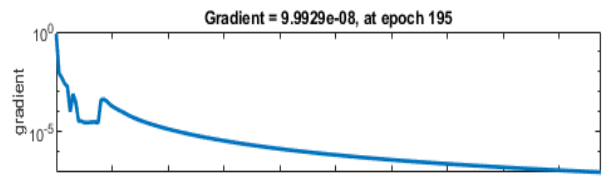

$M u=1 e-09$, at epoch 195

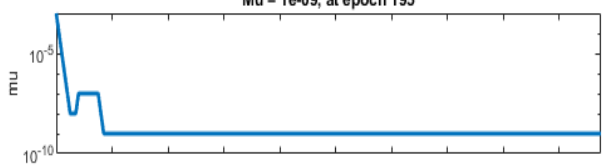

Validation Checks $=0$, at epoch 195

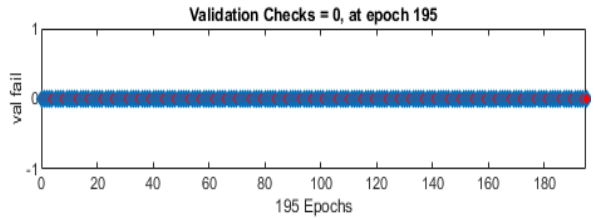

(e) Case 2 EHs

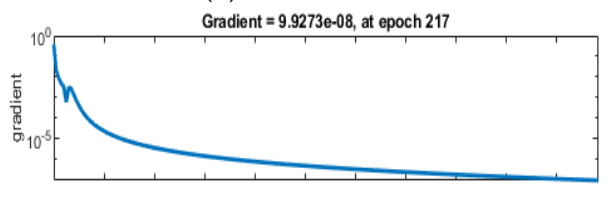

$M u=1 \mathrm{e}-09$, at epoch 217

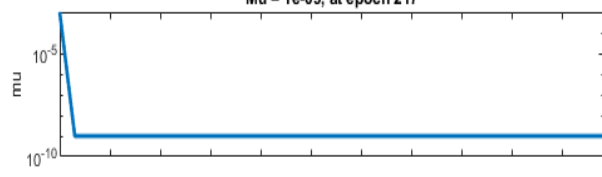

Validation Checks $=0$, at epoch 217

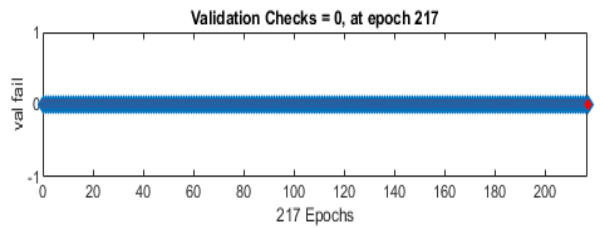

(f) Case $3 \mathrm{EHs}$

Figure 4. Performances of M.S.E (a-c) and State transition $(\mathbf{d}-\mathbf{f})$ to solve the nonlinear COVID-19 spreading model. 


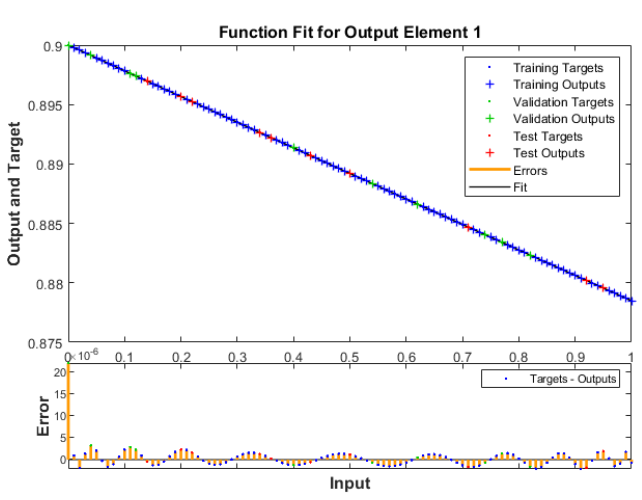

(a) Case 1 Result comparisons

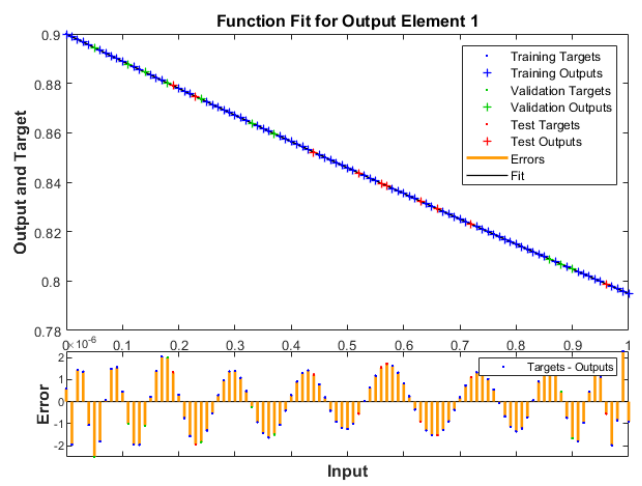

(b) Case 2 Result comparisons

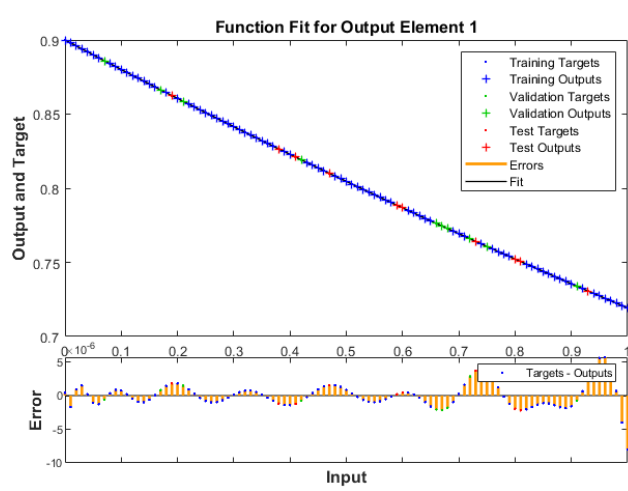

(c) Case 3 Result comparisons

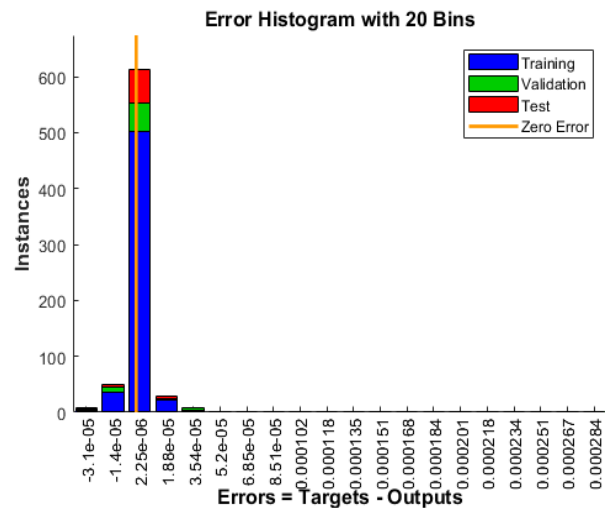

(d) Case $1 \mathrm{EHs}$

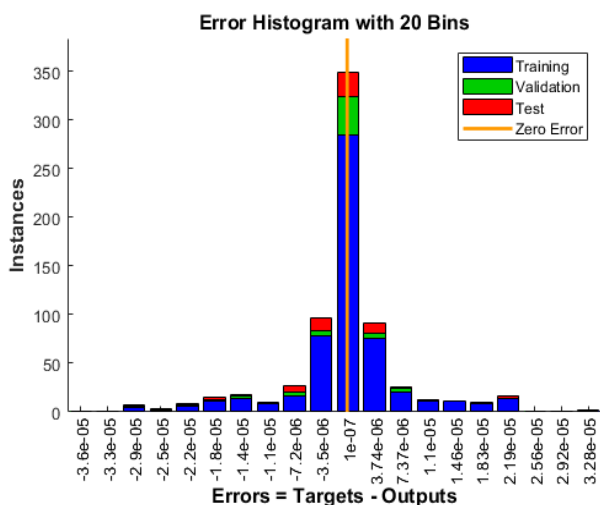

(e) Case 2 EHs

Error Histogram with 20 Bins

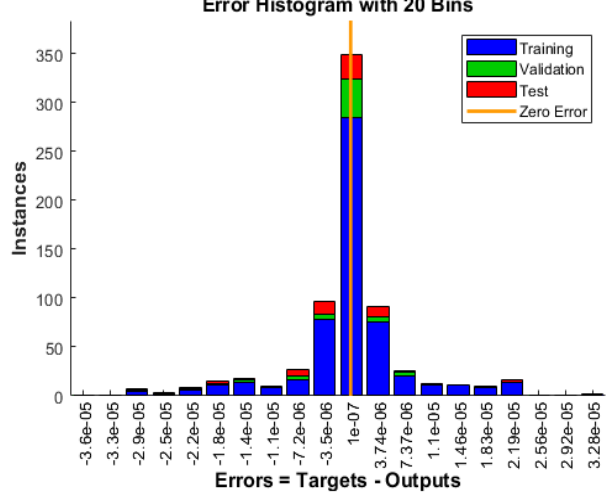

(f) Case $3 \mathrm{EHs}$

Figure 5. Results comparison and EHs to solve the nonlinear COVID-19 spreading model.

Table 1. ANNs-LMB to solve nonlinear the COVID-19 spreading model.

\begin{tabular}{|c|c|c|c|c|c|c|c|c|}
\hline \multirow{2}{*}{ Case } & \multicolumn{3}{|c|}{ M.S.E } & \multirow{2}{*}{ Gradient } & \multirow{2}{*}{ Performance } & \multirow{2}{*}{ Epoch } & \multirow{2}{*}{$\mathbf{M u}$} & \multirow{2}{*}{ Time } \\
\hline & Training & Testing & Validation & & & & & \\
\hline 1 & $1.37 \times 10^{-9}$ & $8.74 \times 10^{-11}$ & $4.71 \times 10^{-10}$ & $9.84 \times 10^{-8}$ & $1.37 \times 10^{-9}$ & 67 & $1 \times 10^{-10}$ & 03 \\
\hline 2 & $9.62 \times 10^{-11}$ & $1.85 \times 10^{-11}$ & $1.33 \times 10^{-11}$ & $9.99 \times 10^{-8}$ & $9.62 \times 10^{-11}$ & 195 & $1 \times 10^{-9}$ & 04 \\
\hline 3 & $9.93 \times 10^{-11}$ & $1.18 \times 10^{-11}$ & $5.71 \times 10^{-12}$ & $9.92 \times 10^{-8}$ & $9.93 \times 10^{-11}$ & 217 & $1 \times 10^{-9}$ & 05 \\
\hline
\end{tabular}



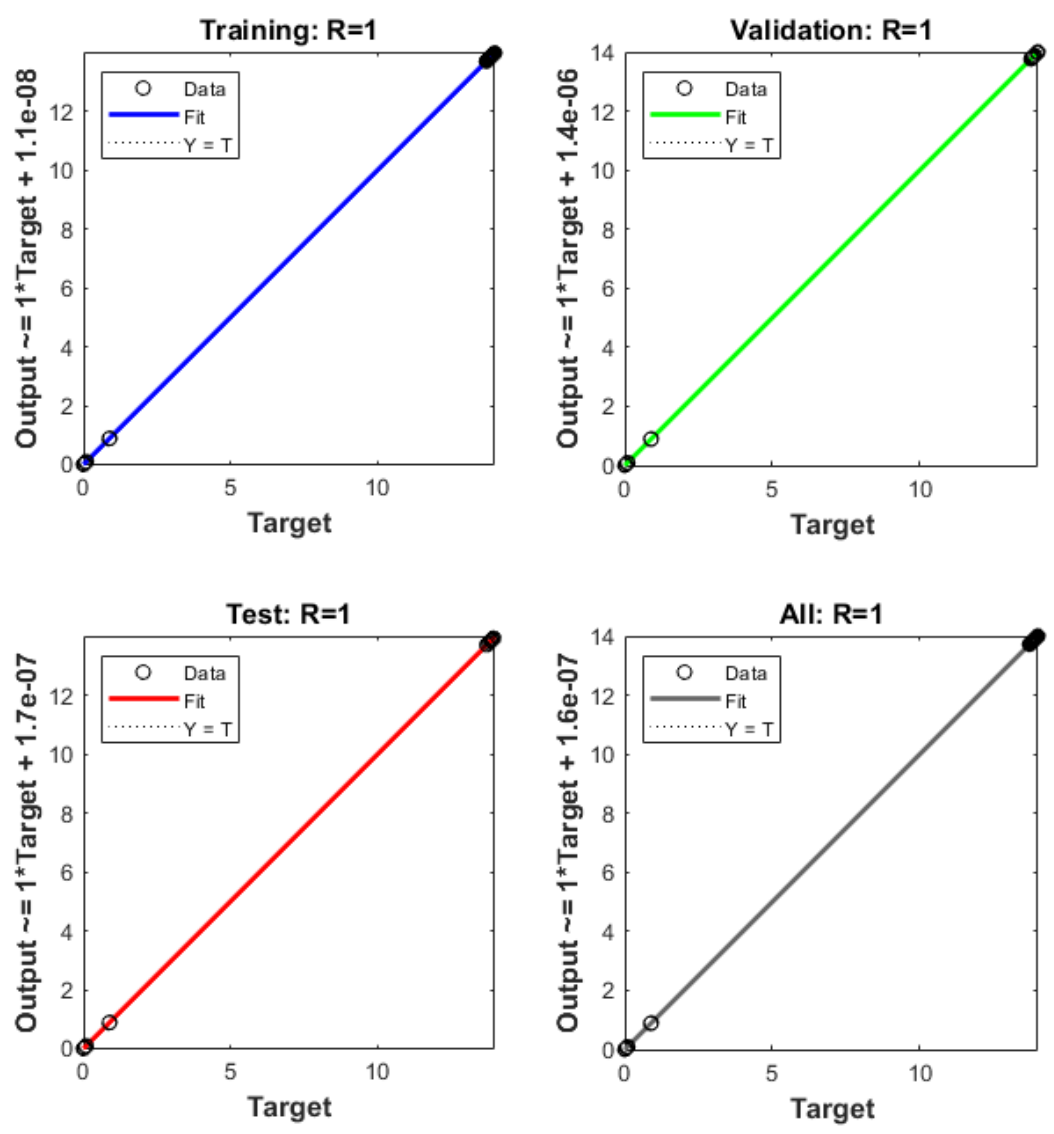

Figure 6. Case 1 Regression plots based on the nonlinear COVID-19 spreading model.

The comparative soundings are demonstrated in Figures 9 and 10 to solve each variant of the nonlinear coronavirus spreading model. The outcomes of the " $S$ ", " $E$ ", " $I$ ", " $R$ ", " $N$ ", " $D$ ", and " $C$ " based on the nonlinear coronavirus spreading model using the ANNs-LMB are drawn in Figure 9a-g. The exact (reference and obtained) matching of the results indicates the precision and exactness of the ANNs-LMB to solve each variant of the nonlinear coronavirus spreading model. The AE performances are drawn in Figure 10 to solve each variant of the nonlinear coronavirus spreading model. The AE of " $S$ ", " $E$ ", " $I$ ", " $R$ ", " $N$ ", " $D$ ", and " $C$ " based on the based on the nonlinear coronavirus spreading model using the ANNs-LMB are drawn in Figure 10a-g. Figure 10a shows the AE for

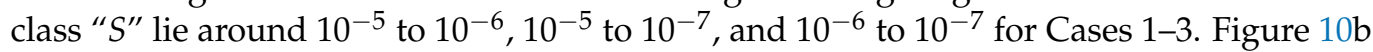
indicates the $\mathrm{AE}$ for the category " $\mathrm{E}^{\prime \prime}$ lies around $10^{-5}$ to $10^{-7}, 10^{-6}$ to $10^{-7}$, and $10^{-6}$ to $10^{-8}$ for the categories 1-3. It is observed in Figure 10c that the AE for the category " $\mathrm{I}^{\text {" lie }}$ around $10^{-5}$ to $10^{-6}, 10^{-6}$ to $10^{-7}$, and $10^{-6}$ to $10^{-8}$ for Cases $1-3$. Figure $10 \mathrm{~d}$ provides

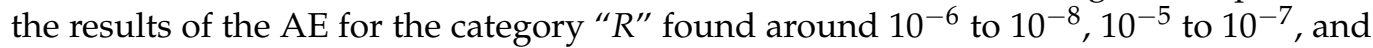
$10^{-6}$ to $10^{-8}$ for Cases 1-3. Figure 10e shows the AE values of the dynamics of $N(y)$ found around $10^{-4}$ to $10^{-6}$ for each case of the nonlinear model. In Figure 10f, it is observed the AE for class " $D$ " lie around $10^{-5}$ to $10^{-7}$ for Case 1, whiles for Cases 2 and 3 , these values found around $10^{-5}$ to $10^{-6}$. In Figure $10 \mathrm{~g}$, it is observed the $\mathrm{AE}$ for class " $\mathrm{C}^{\text {" lie around }}$ $10^{-4}$ to $10^{-6}, 10^{-6}$ to $10^{-10}$, and $10^{-6}$ to $10^{-8}$ for Cases $1-3$. These exactly match the results to perform the exactness and perfection of the ANNs-LMB to solve each variant of the nonlinear coronavirus spreading model. 

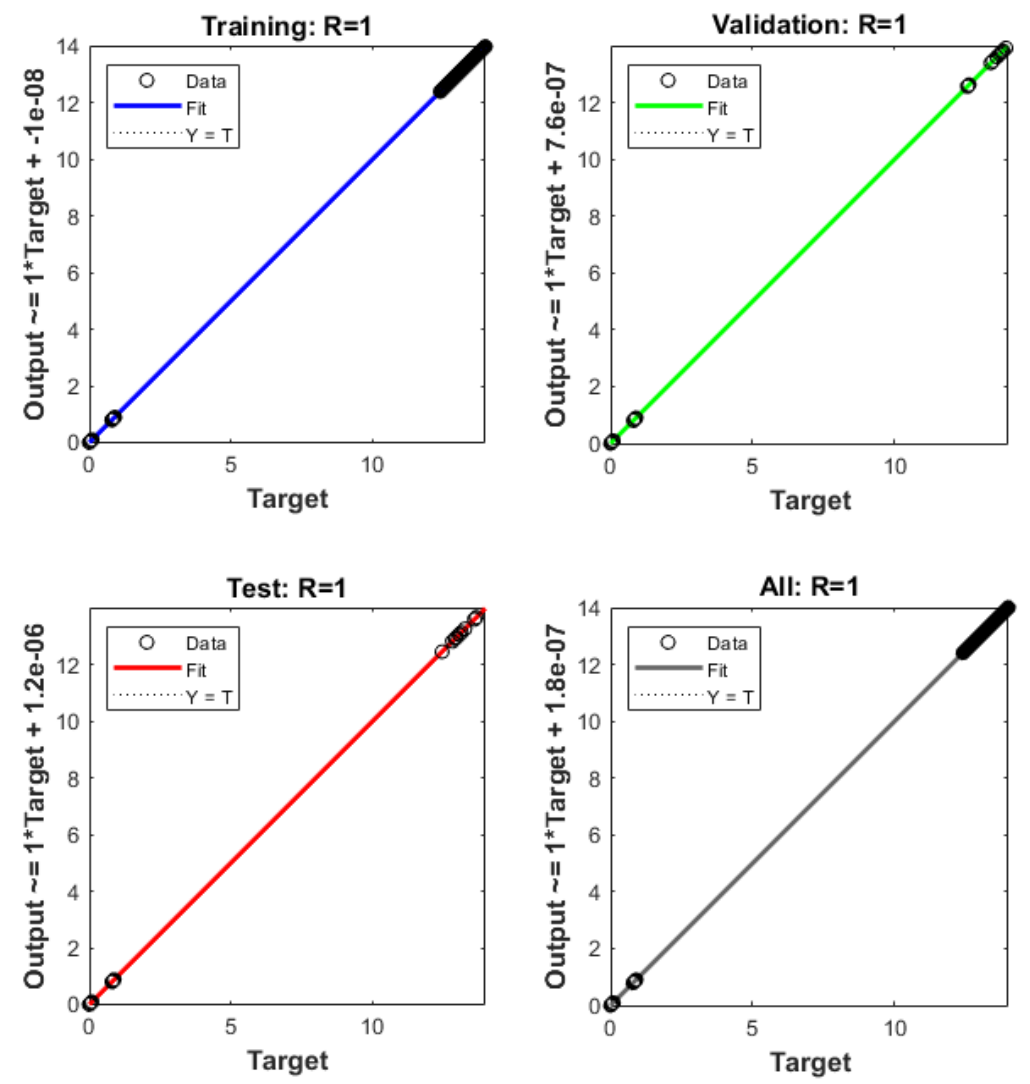

Figure 7. Case 2 Regression plots based on the nonlinear COVID-19 spreading model.
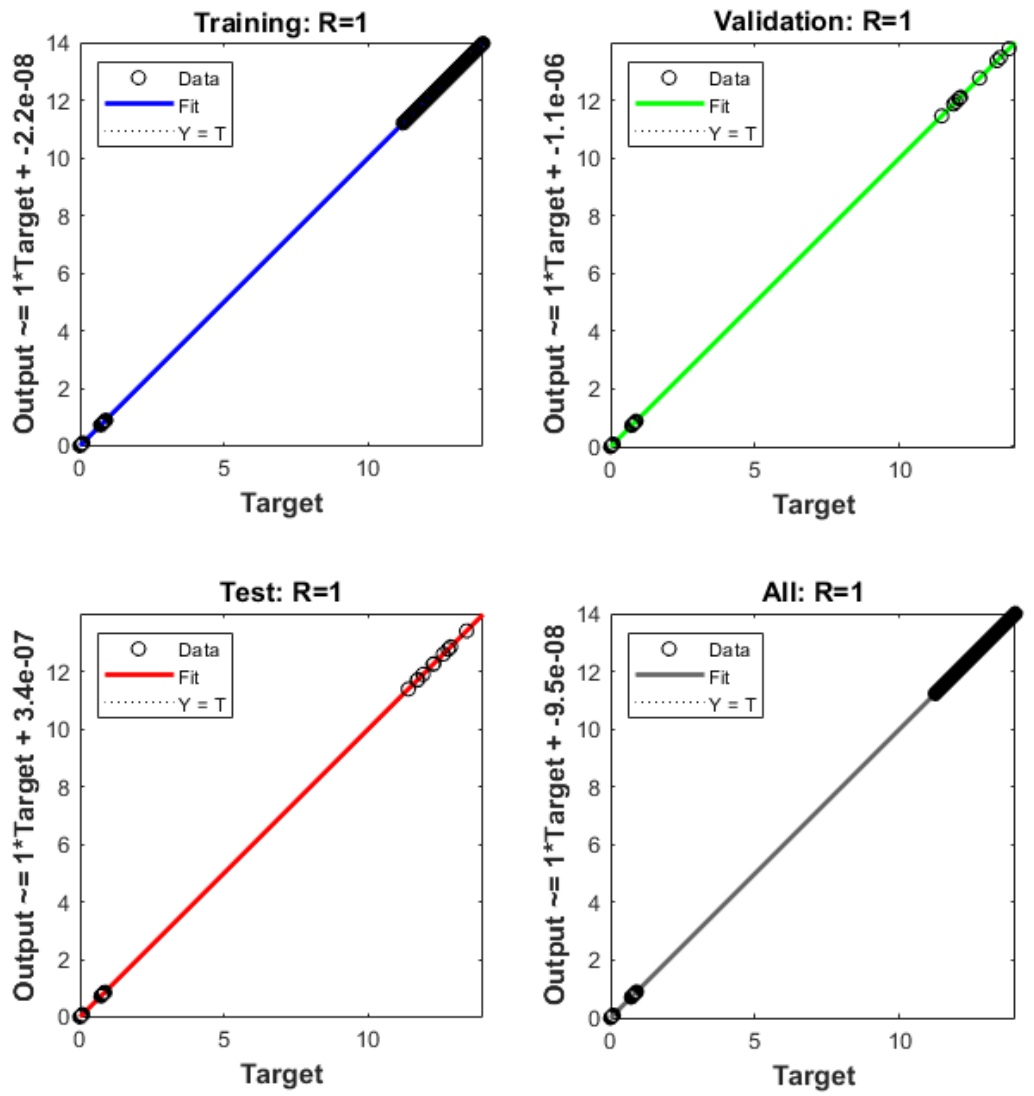

Figure 8. Case 3 Regression plots based on the nonlinear COVID-19 spreading model. 


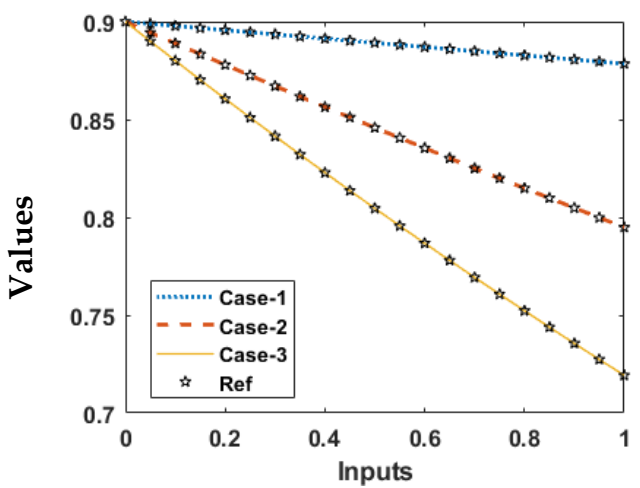

(a) Results of the $S(y)$

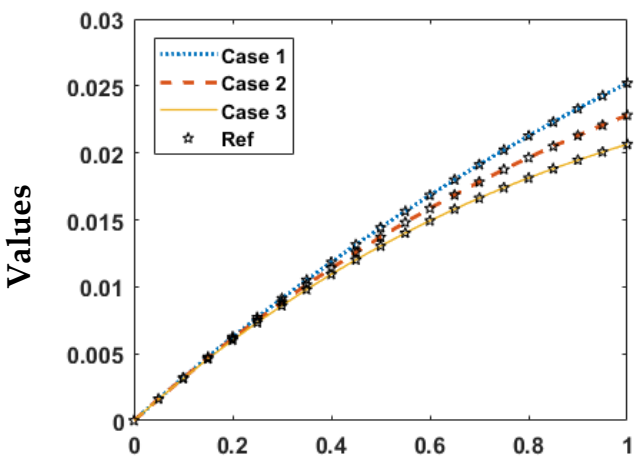

Inputs

(c) Results of the $I(y)$

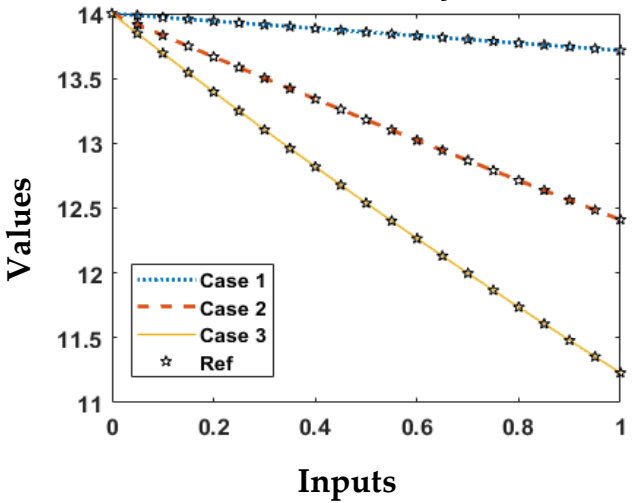

(e) Results of the $N(y)$

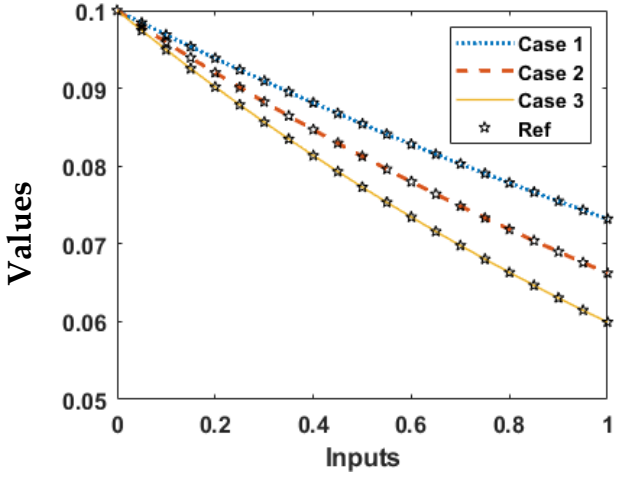

(b) Results of the $E(y)$

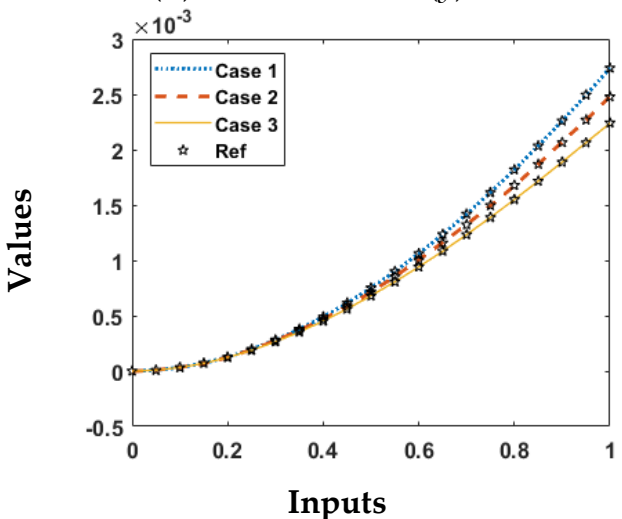

(d) Results of the $R(y)$

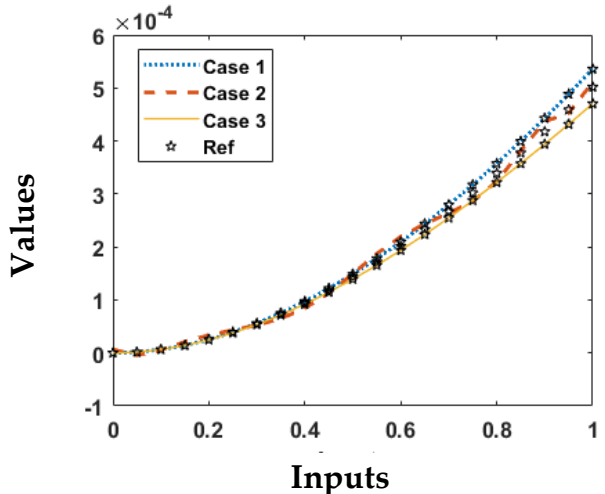

(f) Results of the $D(y)$

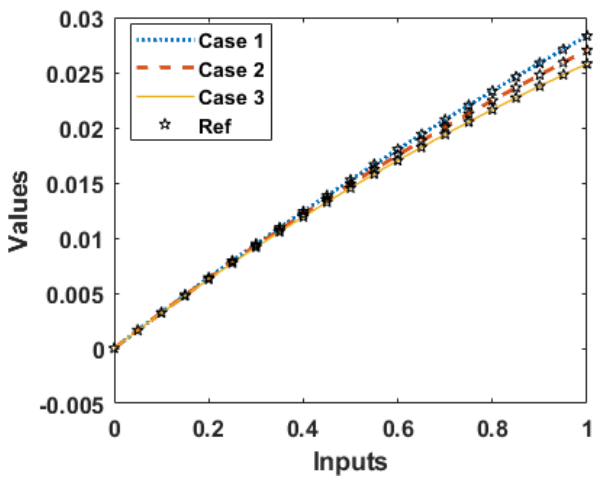

(g) Results of the $C(y)$

Figure 9. Result comparisons using the ANNs-LMB to solve the nonlinear COVID-19 spreading model. 


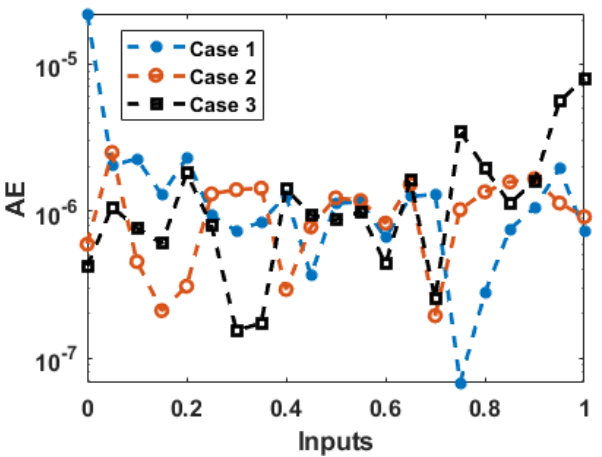

(a) AE the $S(y)$

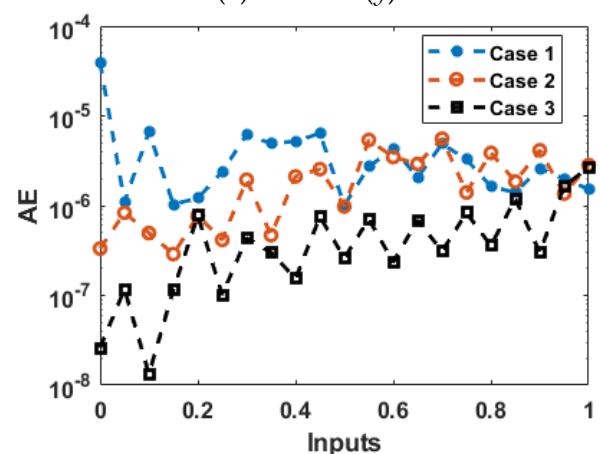

(c) AE for the $I(y)$

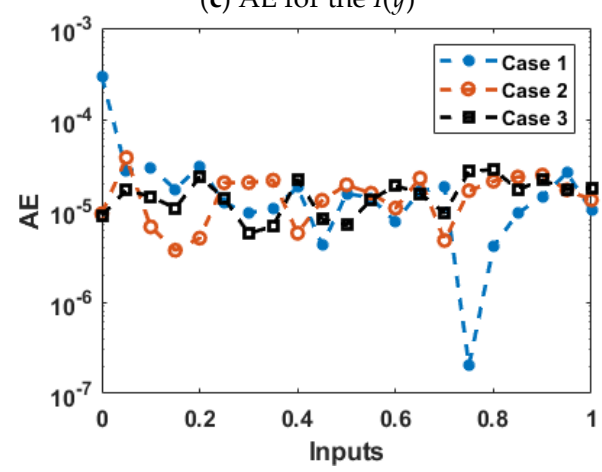

(e) AE for the $N(y)$

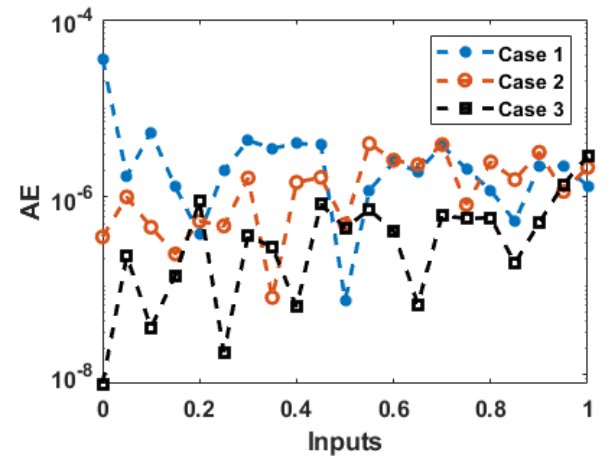

(b) AE for the $E(y)$

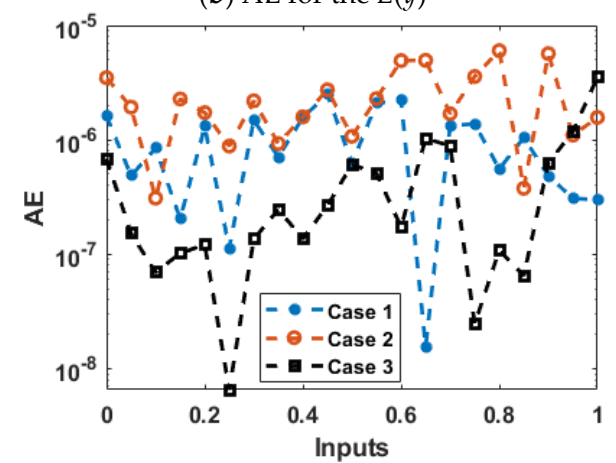

(d) AE for the $R(y)$

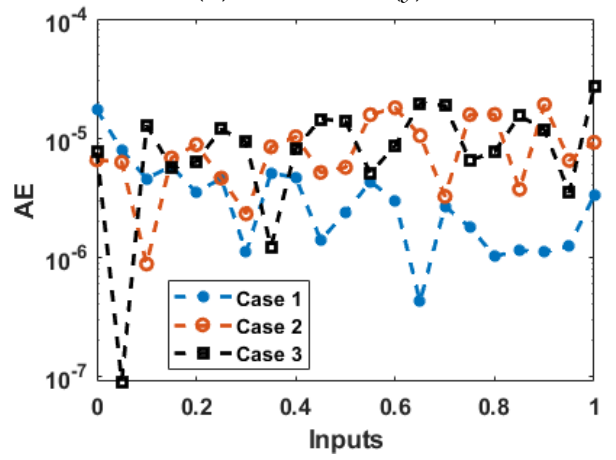

(f) AE for the $D(y)$

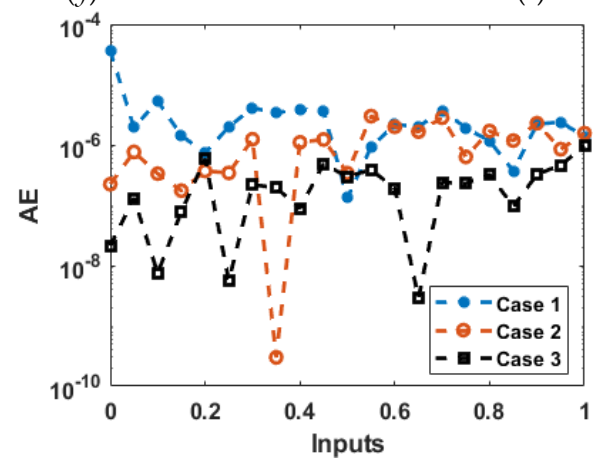

(g)

Figure 10. AE using the ANNs-LMB to solve the nonlinear COVID-19 spreading model.

\section{Conclusions}

The models based on the artificial neural networks are presented, together with the training of Levenberg-Marquardt backpropagation, to solve the nonlinear coronavirus spreading model. The numerical scheme based on the ANNs-LMB is implemented for three different procedures of training, authentication, testing, and sample data. These data proportions are provided to solve three variants of the nonlinear coronavirus spreading model, selected as $80 \%, 10 \%$, and $10 \%$ for training, validation, and testing, respectively. The 
numerical measures have been achieved using the ANNs-LMB, along with the comparative investigations through the reference dataset. The numerical accomplished results from the ANNs-LMB are implemented to reduce the M.S.E. In order to find the exactness, effectiveness, reliability, and capability of the ANNs-LMB scheme, the numerical bases are capable using the proportional actions via M.S.E, correlation, EHs, and regression. The gradient performances using the step size are attained for each variant of the nonlinear coronavirus spreading model. Additionally, the precision and reliability of ANNs-LMB is observed using sufficient large illustrations for numerical and graphical forms through the convergence plots, M.S.E collections, regression dynamics, and EHs.

The designed neuro-evolution based computing strategy is a good alternative to exploit the state of the art on studies related to COVID-19 and dengue modeling and control [39-43].

Author Contributions: Conceptualization, Z.S. and S.J.; methodology, Z.S. and M.A.Z.R.; software, M.U. and Z.S.; validation, M.U., S.J. and H.A.; formal analysis, M.U., Z.S. and S.J.; investigation, M.U. and H.A.; resources, M.A.Z.R., S.K.E. and A.K.; data curation, H.A., S.K.E. and A.K.; writingoriginal draft preparation, M.U., Z.S. and S.J.; writing-review and editing, S.J., S.K.E. and A.K.; visualization, H.A.; supervision, M.A.Z.R. and S.J.; project administration, S.J.; funding acquisition, S.K.E. and A.K. All authors have read and agreed to the published version of the manuscript.

Funding: This work was supported by Taif University Researchers Supporting Project number (TURSP-2020/68), Taif University, Taif, Saudi Arabia.

Institutional Review Board Statement: Not applicable.

Informed Consent Statement: Not applicable.

Data Availability Statement: Not applicable.

Acknowledgments: This work was supported by Taif University Researchers Supporting Project number (TURSP-2020/68), Taif University, Taif, Saudi Arabia.

Conflicts of Interest: All the authors state that there are no potential conflict of interest.

\section{References}

1. Ramani, V.K.; Shinduja, R.; Suresh, K.P.; Naik, R. A Study on the Global Scenario of COVID-19 Related Case Fatality Rate, Recovery Rate and Prevalence Rate and Its Implications for India-A Record Based Retrospective Cohort Study. Adv. Infect. Dis. 2020, 10, 233-248. [CrossRef]

2. Pratiwi, C.D.; Mungkasi, S. Euler's and Heun's numerical solutions to a mathematical model of the spread of COVID-19. AIP Conf. Proc. 2021, 2353, 030110.

3. Donders, F.; Lonnée-Hoffmann, R.; Tsiakalos, A.; Mendling, W.; Martinez de Oliveira, J.; Judlin, P.; Xue, F.; Donders, G.G.G.; ISIDOG COVID-19 Guideline Workgroup. ISIDOG recommendations concerning COVID-19 and pregnancy. Diagnostics 2020, 10, 243. [CrossRef] [PubMed]

4. Wang, J. Mathematical models for COVID-19: Applications, limitations, and potentials. J. Public Health Emerg. 2020, 4, 9. [CrossRef] [PubMed]

5. Rhodes, T.; Lancaster, K. Mathematical models as public troubles in COVID-19 infection control: Following the numbers. Health Sociol. Rev. 2020, 29, 177-194. [CrossRef]

6. Javeed, S.; Anjum, S.; Alimgeer, K.S.; Atif, M.; Khan, M.S.; Farooq, W.A.; Hanif, A.; Ahmed, H.; Yao, S.W. A novel Mathematical model for COVID-19 with remedial strategies. Results Phys. 2021, 27, 104248. [CrossRef] [PubMed]

7. Jewell, B.L.; Mudimu, E.; Stover, J.; Ten Brink, D.; Phillips, A.N.; Smith, J.A.; Martin-Hughes, R.; Teng, Y.; Glaubius, R.; Mahiane, S.G. Potential effects of disruption to HIV programmes in sub-Saharan Africa caused by COVID-19: Results from multiple mathematical models. Lancet HIV 2020, 7, e629-e640. [CrossRef]

8. Sánchez, Y.G.; Sabir, Z.; Guirao, J.L. Design of a nonlinear SITR fractal model based on the dynamics of a novel coronavirus (COVID-19). Fractals 2020, 28, 2040026. [CrossRef]

9. Khrapov, P.; Loginova, A. Comparative analysis of the mathematical models of the dynamics of the coronavirus COVID-19 epidemic development in the different countries. Int. J. Open Inf. Technol. 2020, 8, 17-22.

10. Elsonbaty, A.; SABIR, Z.; RAMASWAMY, R.; ADEL, W. Dynamical analysis of a novel discrete fractional SITRs model for COVID-19. Fractals 2021, 2021, 2140035. [CrossRef]

11. Thompson, R.N. Epidemiological models are important tools for guiding COVID-19 interventions. BMC Med. 2020, 18, 152. [CrossRef] 
12. Umar, M.; Sabir, Z.; Raja, M.A.Z.; Shoaib, M.; Gupta, M.; Sánchez, Y.G. A stochastic intelligent computing with neuro-evolution heuristics for nonlinear SITR system of novel COVID-19 dynamics. Symmetry 2020, 12, 1628. [CrossRef]

13. Umar, M.; Sabir, Z.; Raja, M.A.Z.; Amin, F.; Saeed, T.; Guerrero-Sanchez, Y. Integrated neuro-swarm heuristic with interior-point for nonlinear SITR model for dynamics of novel COVID-19. Alex. Eng. J. 2021, 60, 2811-2824. [CrossRef]

14. Kharis, M. Mathematical modeling of Avian Influenza epidemic with bird vaccination in constant population. J. Phys. Conf. Ser. 2018, 983, 012116. [CrossRef]

15. Yulida, Y.; Karim, M.A. Pemodelan Matematika Penyebaran COVID-19 di Provinsi Kalimantan Selatan. Media Bina Ilm. 2020, 14, 3257-3264.

16. Awan, S.E.; Raja, M.A.Z.; Gul, F.; Khan, Z.A.; Mehmood, A.; Shoaib, M. Numerical Computing Paradigm for Investigation of Micropolar Nanofluid Flow between Parallel Plates System with Impact of Electrical MHD and Hall Current. Arab. J. Sci. Eng. 2021, 46, 645-662. [CrossRef]

17. Sabir, Z.; Guirao, J.L.; Saeed, T. Solving a novel designed second order nonlinear Lane-Emden delay differential model using the heuristic techniques. Appl. Soft Comput. 2021, 102, 107105. [CrossRef]

18. Sabir, Z.; Raja, M.A.Z.; Guirao, J.L.; Shoaib, M. A novel design of fractional Meyer wavelet neural networks with application to the nonlinear singular fractional Lane-Emden systems. Alex. Eng. J. 2021, 60, 2641-2659. [CrossRef]

19. Sabir, Z.; Raja, M.A.Z.; Shoaib, M.; Aguilar, J.G. FMNEICS: Fractional Meyer neuro-evolution-based intelligent computing solver for doubly singular multi-fractional order Lane-Emden system. Comput. Appl. Math. 2020, 39, 303. [CrossRef]

20. Sabir, Z.; Raja, M.A.Z.; Baleanu, D. Fractional Mayer Neuro-swarm heuristic solver for multi-fractional Order doubly singular model based on Lane-Emden equation. Fractals 2021, 29, 2140017-1219. [CrossRef]

21. Umar, M.; Sabir, Z.; Raja, M.A.Z. Intelligent computing for numerical treatment of nonlinear prey-predator models. Appl. Soft Comput. 2019, 80, 506-524. [CrossRef]

22. Umar, M.; Sabir, Z.; Amin, F.; Guirao, J.L.; Raja, M.A.Z. Stochastic numerical technique for solving HIV infection model of CD4+ T cells. Eur. Phys. J. Plus 2020, 135, 403. [CrossRef]

23. Sabir, Z.; Raja, M.A.Z.; Umar, M.; Shoaib, M. Neuro-swarm intelligent computing to solve the second-order singular functional differential model. Eur. Phys. J. Plus 2020, 135, 474. [CrossRef]

24. Sabir, Z.; Manzar, M.A.; Raja, M.A.Z.; Sheraz, M.; Wazwaz, A.M. Neuro-heuristics for nonlinear singular Thomas-Fermi systems. Appl. Soft Comput. 2018, 65, 152-169. [CrossRef]

25. Raja, M.A.Z.; Umar, M.; Sabir, Z.; Khan, J.A.; Baleanu, D. A new stochastic computing paradigm for the dynamics of nonlinear singular heat conduction model of the human head. Eur. Phys. J. Plus 2018, 133, 364. [CrossRef]

26. Umar, M.; Raja, M.A.Z.; Sabir, Z.; Alwabli, A.S.; Shoaib, M. A stochastic computational intelligent solver for numerical treatment of mosquito dispersal model in a heterogeneous environment. Eur. Phys. J. Plus 2020, 135, 565. [CrossRef]

27. Sabir, Z.; Khalique, C.M.; Raja, M.A.Z.; Baleanu, D. Evolutionary computing for nonlinear singular boundary value problems using neural network, genetic algorithm and active-set algorithm. Eur. Phys. J. Plus 2021, 136, 195. [CrossRef]

28. Sabir, Z.; Raja, M.A.Z.; Guirao, J.L.; Shoaib, M. A Neuro-Swarming Intelligence-Based Computing for Second Order Singular Periodic Non-linear Boundary Value Problems. Front. Phys. 2020, 8, 224. [CrossRef]

29. Bhattacharyya, A.; Chakraborty, T.; Rai, S.N. Stochastic forecasting of COVID-19 daily new cases across countries with a novel hybrid time series model. medRxiv 2021. [CrossRef]

30. Braga, M.D.B.; Fernandes, R.D.S.; Souza, G.N.D., Jr.; Rocha, J.E.C.D.; Dolácio, C.J.F.; Tavares, I.D.S., Jr.; Pinheiro, R.R.; Noronha, F.N.; Rodrigues, L.L.S.; Ramos, R.T.J.; et al. Artificial neural networks for short-term forecasting of cases, deaths, and hospital beds occupancy in the COVID-19 pandemic at the Brazilian Amazon. PLoS ONE 2021, 16, e0248161. [CrossRef] [PubMed]

31. Apostolopoulos, I.D.; Mpesiana, T.A. Covid-19: Automatic detection from X-ray images utilizing transfer learning with convolutional neural networks. Phys. Eng. Sci. Med. 2020, 43, 635-640. [CrossRef] [PubMed]

32. Ozturk, T.; Talo, M.; Yildirim, E.A.; Baloglu, U.B.; Yildirim, O.; Acharya, U.R. Automated detection of COVID-19 cases using deep neural networks with X-ray images. Comput. Biol. Med. 2020, 121, 103792. [CrossRef]

33. Saba, A.I.; Elsheikh, A.H. Forecasting the prevalence of COVID-19 outbreak in Egypt using nonlinear autoregressive artificial neural networks. Process Saf. Environ. Prot. 2020, 141, 1-8. [CrossRef]

34. Shoaib, M.; Raja, M.A.Z.; Sabir, M.T.; Bukhari, A.H.; Alrabaiah, H.; Shah, Z.; Kumam, P.; Islam, S. A stochastic numerical analysis based on hybrid NAR-RBFs networks nonlinear SITR model for novel COVID-19 dynamics. Comput. Methods Programs Biomed. 2021, 202, 105973. [CrossRef]

35. Siddiqui, M.K.; Islam, M.Z.; Kabir, M.A. A novel quick seizure detection and localization through brain data mining on ECoG dataset. Neural Comput. Appl. 2019, 31, 5595-5608. [CrossRef]

36. Naz, S.; Raja, M.A.Z.; Mehmood, A.; Zameer, A.; Shoaib, M. Neuro-intelligent networks for Bouc-Wen hysteresis model for piezostage actuator. Eur. Phys. J. Plus 2021, 136, 396. [CrossRef]

37. Ahmad, I.; Ilyas, H.; Raja, M.A.Z.; Khan, Z.; Shoaib, M. Stochastic numerical computing with Levenberg-Marquardt backpropagation for performance analysis of heat Sink of functionally graded material of the porous fin. Surf. Interfaces 2021, $26,101403$. [CrossRef]

38. Shoaib, M.; Raja, M.A.Z.; Jamshed, W.; Nisar, K.S.; Khan, I.; Farhat, I. Intelligent computing Levenberg Marquardt approach for entropy optimized single-phase comparative study of second grade nanofluidic system. Int. Commun. Heat Mass Transf. 2021, 127, 105544. [CrossRef] 
39. Markovič, R.; Šterk, M.; Marhl, M.; Perc, M.; Gosak, M. Socio-demographic and health factors drive the epidemic progression and should guide vaccination strategies for best COVID-19 containment. Results Phys. 2021, 2021, 104433. [CrossRef]

40. Gosak, M.; Duh, M.; Markovič, R.; Perc, M. Community lockdowns in social networks hardly mitigate epidemic spreading. New J. Phys. 2021, 23, 043039. [CrossRef]

41. Priesemann, V.; Balling, R.; Brinkmann, M.M.; Ciesek, S.; Czypionka, T.; Eckerle, I.; Giordano, G.; Hanson, C.; Hel, Z.; Hotulainen, P.; et al. An action plan for pan-European defence against new SARS-CoV-2 variants. Lancet 2021, 397, 469-470. [CrossRef]

42. Javeed, S.; Ahmed, A.; Javed, M.A.; Khan, M.S. Stability analysis and numerical solution of dengue model. Punjab Univ. J. Math. 2021, 50, 45-67.

43. Ahmad, S.; Javeed, S.; Ahmad, H.; Khushi, J.; Elagan, S.K.; Khames, A. Analysis and numerical solution of novel fractional model for dengue. Results Phys. 2021, 28, 104669. [CrossRef] 